That cautious inquirer is not, however, yet satisfied. He asks " if during contraction an increase of strain produces an increase in the total chemical processes (metamorphosis) of the muscle, are we to think that the effect of the strain ceases to be felt immediately the contraction is finished, and is not carried on into the period of relaxation?

And moreover, putting the matter to an experimental inquiry, he finds, as a matter of fact, that when two muscles are treated as in Fick's experiment, one strained at all times, and the other strained only during contraction, the amount of chemical change taking place in the first, as evidenced by the generation of acid, is distinctly larger than in the second. So there the question remains for the present.

\section{THE PROZECTED CHANNEL RAILWAYS}

THE first question to be asked about a railway between England and France would be properly one upon its importance, and on the value of such a railway to the social and commercial interests of the two countries.

Let us consider the present situation and the circumstances which would affect, favourably or otherwise, a Channel Railway.

A sheet of water, impassable at all times to the bulk of a people, although a highway of their sailors, is a most effectual barrier between two countries. Free intercourse is checked; the exchange of ideas and thought Jimited to a small class of traders and travellers, not to mention the learned, who in all countries form but a minority of the people.

Two nations so situated are generally cold towards each other, and in time materially differ in their mode of living, in their ideas, habits, and in their institutions. A free intercourse need not necessarily obliterate the peculiarities of different races; but it has always been an effective means of moderating prejudices.

To attempt a description of the numerous and subtle ways by fwhich the mind of populations may be taken hold of-and even be guided-would be beyond our present object; but as a means of self-education and consequent civilisation, there could not be a more powerful instrument than railways, because they offer the readiest, most convenient, and the cheapest means of communication between one individual and another.

Half-a-century ago the bulk of a nation was enclosed within its own walls; only a small minority could afford to travel and to observe, to exchange and to induce thought. That in which all schools must necessarily fail, or at least can succeed but indifferently-viz., the education of the million-railways are accomplishing with extraordinary rapidity; their civilising influence is constantly at work: they cover England more than any other country, and accordingly England derives all the benefit which that institution may confer on a people. Railways are also in a great measure covering France, Belgium, Germany, \&c. ; but there is an essential difference between the effect which they may produce in England and on the Continent. In England they interchange and mix the ideas and habits principally of the Anglo-Saxon race, some twenty odd millions; on the Continent they cause to mingle several great nations of different race: certainly more than sixty millions are there under the operation of railways as an institution.

The civilising influence of railways is, in England, accordingly confined to one groove - one main AngloSaxon line-and the effect on the English people cannot but remain elementary : on the Continent, however, their civilising power derives its material from several distinct and essentially different sources, viz., the Teutonic and Gallic races, and some others of minor consequence, the material of which, interwoven and allied by the affinity of thought, forms a compound of a different nature and character, differing as much as compounds differ from their elements.

That these causes have been in operation in the manner indicated, we may easily trace in the relative progress made within one generation in England and on the Continent. When railways were in their infancy; England was, in her institutions and industry, much ahcad of any country. Railways have improved the condition of every people, but has the improvement not been very much greater on the Continent? It may be urged, that there was more room for improvement in those countries: that may be so, but this would not affect the case, for there was and is room enough for improvement at home.

Within one generation railways have produced wonderful revolutions on the Continent. The despotic governments of several great nations have given way to truly liberal institutions; continental industry rivals already that of England. And how was all that brought about? The immediate causes of these changes may seem innumerable; and yet, there is only one great cause at the bottom of all this change, viz. enlightenment of the people; and we claim a large share of this result for the institution of railways.

If, then, the combination of thought originating from different sources has so much advanced and civilised the Continent, what would be the effect upon England if a railway could suddenly bring the bulk of her people in close contact with the continental nations? A more complex, a higher compound would be formed, and what the ultimate effect of this change might be the future alone could tell; all that can be said with certainty at present is this, that enlightemment must follow in a potential form. Excursion trains would take the million to and from either country; excursions to and from Paris would be made with the same convenience and comfort as now between Manchester, Liverpool, London, and other large towns; in short, the social effect of the change would be immense; and how would it affect the commercial interests? Enough has already been said to show that a channel railway in good working condition would accomplish wonders, and it may be easily perceived that, though all will be gainers by the change, England would gain the most.

This being so, then, the next point is to analyse the different projects which have been proposed for bringing the result about. Among these, the Bridge scheme has naturally received considerable public attention. To the non-professional mind it appears a plausible proposition, and enough support has been given to its promoters to enable them to promise wonders.

We have no definite plan of the proposed bridge, but we have a Channel Bridge Company; we have not even a definite outline of the main engineering features, but we have the assurance of the success of a model which, in the opinion 
of the projector, might be enlarged to any extent. The span of the bridge is evidently not agreed upon, nor is the construction of the piers determined; we are assured that we may have any span we like, and that there is no difficulty about the piers; in fact, the only thing wanted to complete this great national work in three years, appears to be a subscription of eight millions sterling to the credit account of the Channel Bridge Company.

The vagueness of the scheme is the safeguard of its promoters. We cannot even describe the propositions without running the risk of being contradicted on every point ; it is even intimated that it is premature to discuss the scientific questions of the Channel Bridge scheme.

We have a few facts, however, on which we may safely enlarge. It is admitted, that from Dover to Blanc Nez, a distance of twenty-one miles, a number of piers are indispensable. In $\mathrm{I} 868$, the distance was to be crossed by ten spans, each over 9,000 feet in the clear, and we have a diagram of that monster bridge. In I 869 rumour will have it that the number of spans is to be increased from ten to thirty, making the reduced span still over 3,000 feet in the clear. With the first proposition we should have had nine piers, with the latter, twenty-nine, washed by the waters of the Channel.

Whatever the ultimate number of piers may, be, it is erident that some of them must be constructed in water exceeding 30 fathoms, or 180 feet in depth (according to the Admiralty Chart); moreover, these piers are to be 360 feet above high water, making the total height of the structure of some of them over 540 feet from the bottom of the Channel. Let us see how one of these pyramids is to be constructed midway the Channel.

The projector discards masonry, for no operations I 80 feet below water level are practicable; $;$ and as the foundations themselves would have to be carried down another indefinite number of feet, the depth and consequent pressure would render life, and therefore work, impossible.

A new construction of piers had to be invented, and herein should be found the virtue of the design; let the agents of the Channel Bridge Company tell their story:-

The project clepends in effect on two remarkable imovations in the construction and establishment of the piers and metallic beams. In addition to the considerable height to which the former rise above the water (120 yards), the bases of the piers are sunk to the bottom at a depth varying from 28 to 52 yards. Except the centre one, all the piers at their foundations measure 130 yards in width and 87 yards in length, diminishing upwards, and forming at the summit a square of 66 yards on each sicle. The centre pier will be half as large again as the others. All the pieces composing the work are of cast-iron, and furnish, without increasing the weight, a power of resistance superior to all other kinds of construction.

As such ponderous piers could not be erected by the ordinary means, $M$. Boutet proposes to construct on the shore their lower parts or bases to a height sufficient to rise ten yards above high water, and as soon as the iron skeleton is put together and bolted, a number of large sheet-iron buoys are distributed about the immense surface of the base. At low water the metallic framework thus prepared is macle to slicle upon the shore to lowwater mark. The tide, in rising, raises this raft or base of iron lightened by the buoys, and floats it. A tug steamer then removes it to its place, previously indicated by one of a line of buoys attached to an iron cable, stretched across the Straits at a depth of eighteen yards. By raising one of the buoys attached to the raft it is made to descend very slowly, the top being just above the level of the sea when the base touches the bottom. Thus are avoided all the preliminary works under water, which constitute the greatest difficulty in the way of a bridge across the Channel.
Certainly, we have hẹre Baron Munchatisen over again. These cast-iron piers, with a base of $390 \mathrm{ft}$. by $260 \mathrm{ft}$, over $200 \mathrm{ft}$. high, we are informed, are to weigh about 2,500 tons, What is the thickness of their metal to be? Information is wanting on this point; but an iron structure of these dimensions, to bed itself on the bottom of the Channel, could not be designed of less than ten times the weight named.

Assuming, for the sake of argument, that the rise of the tide would float that structure away by the means above described-and our business is to analyse the project as it is, not to suggest or attempt to improve on it-may we not ask with surprise, where would the centre of gravity of this floating structure be? Its centre of gravity would be about ninety feet above the level of the water, and at least one hundred feet above the centre of displacement, Why do our ships not upset, what insures their stability, and why do they right themselves? Mainly, because their centre of gravity is in its lowest position, below their centre of displacement. Here, however, we have a floating structure in which the centre of gravity would be enormously above the centre of displacement, and in its highest position. A slight oscillation, a breath of wind would overturn it, and suppose it could be floated away from shore, it would topple over-right itself upside down; the "sheet-iron buoys" would be uppermost, and the structure below them, forming a gigantic wreck somewhere in the Channel.

So much, then, about the piers. It may give the ordinary reader an idea of the character of this scheme. Shall we say anything about the 9,000 and odd feet clear span? At first sight it appears to be a typographical error; surely 900 and odd feet were meant; but then we meet with the fact of the Channel being divided into ten spans, so there is no getting out of it.

The whole proposition is the offspring of a highly imaginative mind. Of all the schemes or suggestions to cross the Channel by rail, this is the most incoherent. There is nothing in it-not one point of merit. It is not bold, because it lacks the spirit of boldness, viz. Sense. Not a trace of an engineer's mind is to be found in it. Our asylums produce innumerable schemes of this kind, but they are not permitted to disturb the public mind. It is a relief to have done with it. We are glad to say there are several projects which do not lack either sense or ability on the part of the originators. Some of them appear practicable, and one or two highly promising of success, and these will form the subject of our next communication.

\section{DANA'S MINERALOGY \\ A System of Mineralogy: Descriptive Mineralogy com- prising the most Recent Discoveries. By James Dwight Dana, Silliman Professor of Geology and Mineralogy in Yale College, etc., aided by George Jarvis Brush, Professor of Mineralogy and Metal- lurgy in the Sheffield Scientific School of Yale Col- lege. Fifth edition, 8 vo, pp. 827 , figures 617 , (London: Trubner \& Co.) \\ I.}

FORTY years ago mineralogy was a fashionable subject in England; wealthy people collected minerals, though probably but few of those who did so ever made mineralogy a serious study. But mineralogy, under the 